\title{
The Effect of Preemptive Oral Celecoxib on Pain Reduction and Opioid Consumption
}

\section{during Elective Herniorrhaphy}

Maziar Mahjoubifard MD', Hasan Enayati MD², NoorMohammad Noori MD³, Mahdy Shaikh $\mathrm{MD}^{4}$, and Alireza Jahangiri Fard $\mathrm{MD}^{5^{*}}$

'Assistant professor of Anesthesiology, Fellowship in cardiac anesthesiology, Children and Adolescents' Health Research Center, Zahedan University of Medical Sciences, Zahedan, Iran

${ }^{2}$ Assistant professor of Anesthesiology, Zahedan University of Medical Sciences, Zahedan, Iran

${ }^{3}$ Professor of Pediatric Cardiology, Children and Adolescent Health Research Center, Aliebne Abitaleb Hospital, Zahedan University of Medical Sciences, Zahedan, Iran

${ }^{4}$ Anesthesiologist, Department of Anesthesiology, Zabol University of Medical Sciences, Zabol, Iran

${ }^{5}$ Assistant Professor of Anesthesiology, Fellowship of Cardiac Anesthesia, Tracheal Diseases Research Center, National Research Institute of Tuberculosis and Lung Diseases (NRITLD) ,Shahid Beheshti University of Medical Science, Tehran, Iran

*Corresponding author: Alireza Jahangiri Fard MD, Assistant Professor Citation: Mahjoubifard M, Enayati H, Noori N, Mahdy S, Jahangiri Fard of Anesthesiology, Fellowship of Cardiac Anesthesia, Tracheal Diseases Research Center, National Research Institute of Tuberculosis and Lung Diseases (NRITLD), Shahid Beheshti University of Medical Science, Tehran, Iran; E-mail: omidjahangiri_55@yahoo.com

Received Date: $06^{\text {th }}$ November 2015

Accepted Date: $07^{\text {th }}$ January 2016

Published Date: $11^{\text {th }}$ January 2016

A (2016) The Effect of Preemptive Oral Celecoxib on Pain Reduction and Opioid Consumption during Elective Herniorrhaphy. Enliven: J Anesthesiol Crit Care Med 3(1): 001.

Copyright: @2016 Dr. Alireza Jahangiri Fard. This is an Open Access article published and distributed under the terms of the Creative Commons Attribution License, which permits unrestricted use, distribution and reproduction in any medium, provided the original author and source are credited.

\begin{abstract}
Introduction

Pain control is an important aspect in postoperative care. While opioids proved excellent analgesia undesirable side effects such as respiratory depression, nausea and vomiting, constitute major limitation. As a result, many surgical centers used NSAIDs for controlled acute pain of surgery. Celecoxib is NSAIDs that inhibits cox2, but it does not have GI side effect and coagulopathy disorder. The aim of this study was to determine the effect of preemptive celexib on pain score reduction and opioid consumption after herniorrhaphy.

\section{Material and Method}

This is a randomised double blinded clinical trial study which performed in Imam Ali and Khatam hospital in zahedan. 76 patients scheduled for elective herniorrhaphy were enroled in this study. Patients were divided into 2GROUPS; celexib group $(\mathrm{n}=38)$ and placebo group ( $\mathrm{n}=38)$. Drugs (placebo or $200 \mathrm{mg}$ celexib) were given (oraly) 2 hours before operation to patients. All patients general anesthetized with midazolam (1-2mg), fentanyl (1-2 $\mu \mathrm{g} / \mathrm{kg})$ for premedication; nesdonal (4-6mg $/ \mathrm{kg})$ and atracorioum $(0.5 \mathrm{mg} / \mathrm{kg})$ for induction and propofol $(100-200 \mu \mathrm{g} / \mathrm{kg})$ for maintenance. Then pain score (vas score), heart rate, blood pressure was recorded in $2^{\text {nd }}, 6^{\text {th }}, 12^{\text {th }}$ and $24^{\text {th }}$ hours after tracheal extubation. Pain was treated with morphin $0.1 \mathrm{mg} / \mathrm{kg}$ in patients with vas score $>4$. Total Opioid consumption was recorded for 24 hours.
\end{abstract}

Results

Mean painless time in celexib group was higher than placebo group $\{12.7 \pm 9.8$ to $5.38 \pm 8.3(\mathrm{p}=0.04)\}$ and mean pain score of $2^{\text {nd }}$ hour in the celexib group was lower than placebo $\{2.2 \pm 2.2$ to $5.7 \pm 3.5(\mathrm{p}=0.003)\}$. The mean opioid used in celexib group was lower than placebo group $\{5.33 \pm 6.1$ to $11.15 \pm 7.1$ $(\mathrm{p}=0.02)\}$. But difference in mean of HR and BP between two groups wasn't significant.

\section{Conclusion}

Preemptive clexib to be able to reduce pain score and consumption of opioid after hernirrhaphy.

Keywords: Celecoxib; Preemptive analgesia; Herniorrhaphy 


\section{Introduction}

Almost $80 \%$ of patients report moderate to severe pain following surgeries including conventional herniorrhaphy which makes analgesia much important in this regard [1]. Surgery, due to direct tissue damage, almost always causes a release in histamine and other inflammatory mediators which could, in turn, stimulate many peripheral pain receptors in the body. Continuous stimulations by acute sever pain finally pulls down the threshold of pain while facilitating pain hyper sensitization to amplify the present pain. This is the main cause of difficult pain control after surgery and preemptive analgesia requirement [2]. Pre-emptive analgesia is a well-known technique done through using systemic medications or several procedures before surgery. Opioids, ketamine, NSAIDs and other similar drugs are often tried by the technique. Impaired platelet aggregation and GI mucus damagerestrict the use of NSAID usually. Fortunately, dedicated COX2 inhibitors like celecoxib have been one of the famous solutions in this regard through recent decades as pain killer, anti-inflammatory, and antipyretic medications with no serious side effects. There are just a handful of trials to assess pre-emptive effects of celecoxib [3,4]. Through some studies on knee surgeries like arthroplasty or arthroscopy, celecoxib has actually reduced opioid consumption by half during the first 24 hours from the operation [5]. Celecoxib also was shown that could decrease the use of opioids by $40 \%$ as well as keeping the VAS score below 3 during the first 48 hours after surgery [6]. Disregarding the side effects, celecoxib sounds to outpace diclofenac in pain control through perineal repair after childbirth [7].

Considering pre-emptive analgesia as a regulator technique in pain and its pathologic process as well as the prominent role of celecoxib, with a 11hour half-life, the present performance headed to study the effect of the medication in pain control and opioid consumption decrease after inguinal herniorrhaphy.

\section{Materials and Methods}

Through a randomized controlled clinical trial, patients to be candidate for inguinal herniorrhaphy referred to two university hospitals in Zahedan, a district in Southeast of Iran enrolled the trial before being divided into case and control groups each containing 38 patients.

Seventy six candidates between 15 and 65 years with ASA class I, II who were considered for elective inguinal unilateral herniorrhaphy were recruited by this double blind study. All the patients were encoded by randomized numbers before being divided into two groups of control and intervention based on their odd and even numbers. Each group contained 38 patients. Celecoxib with $200 \mathrm{mg}$ dosage was prescribed for the patients in the case group while $200 \mathrm{mg}$ placebo was used per dose in the control group two hours before the surgery started. The operation technique was the same for all the clients disregarding the groups which the patients were in. Patients with allergy to aspirin, history of peptic ulcers in addition to the cases of addiction, lithium treatment, renal function issues, and people with $<40 \mathrm{~kg}$ or over 100 $\mathrm{kg}$ of weight were excluded.

\section{Preoperative Preparation}

The patients got $1-2 \mu \mathrm{g} / \mathrm{kg}$ intravenous fentanyl plus $1-2 \mathrm{mg}$ intravenous midazolam as premedication. Then, $5-6 \mathrm{mg} / \mathrm{kg}$ tiopental sodium was used for induction and $0.5 \mathrm{mg} / \mathrm{kg}$ atracurium was considered as the relaxant and that all was followed by $100-200 \mu \mathrm{g} / \mathrm{kg}$ propofol as the maintenance of the analgesia during the operation. The VAS score was assessed for pain severity at the points of $2,6,12$, and 24 hours after the surgery to prescribe $0.1 \mathrm{mg} /$ $\mathrm{kg}$ intravenous morphine in the case of scores $>4$. Patients' vital signs were carefully monitored and recorded as well as the total opioid consumption. Three participants did not agree to be generally anesthetized and two used morphine during their operation that all were excluded from the study.

Ethics

All the participants signed their written informed consents after getting exclusive explanations about the aim and steps of the study and its importance by the principal investigator. They also were ensured that all the private data would be safely kept by the investigators. Celecoxib is a popular medication in the Iranian pharmacopoeia and its therapeutic and adverse effects are well-known. Furthermore, opioids were considered in any case of failure in pain control. So, Patients were completely safe against severe acute pain.

\section{Statistics}

Data entered SPSS for windows before being analyzed and reported by central tendency indicators using independent t-test and Chi-square test. Paired t-test was utilized in the case of comparison of pain scores in the same group at different points and periods of time. The significance was $\mathrm{P}$ Value $=0.05$ considering $95 \%$ confidence interval and type 1 error of 0.05 .

\section{Results}

The mean age did not differ between the groups (34.92 in controls vs. 30.86 in cases) $(\mathrm{P}=0.347)$. Only 2 out of the all participants were females and consequently this study has nothing to say about the effects of celecoxib in different genders.

In terms of pain score, the mean of the VAS score after 2 hours was 5.7 by placebo but 2.2 by celecoxib with a significant difference $(\mathrm{P}=0.003)$ (Figure 2). Unlikely, the scores were not different too much after 6 hours $(\mathrm{P}=0.3)$. These non-significant results continued later in cases. However, the mean of the total VAS score differed between the groups $(\mathrm{P}=0.047)$ with the showed values in figure 1 . The postoperative painless period of time in cases doubled the time which the controls experienced $(\mathrm{P}=0.045)$ as can be seen in figure 2 . The participants in the control group got half case patients' opioids $(\mathrm{P}=0.047)$ and it is illustrated by figure 3 .

Concerning the adverse effects, heart rate was not different statistically between the groups at any point of study (figure 6). Disregarding the data after $24^{\text {th }}$ hour $(\mathrm{P}=0.04)$, the mean of blood pressure did not significantly differ in the studied groups 2,6 , and 12 hours after surgery showed in figure 4 . 


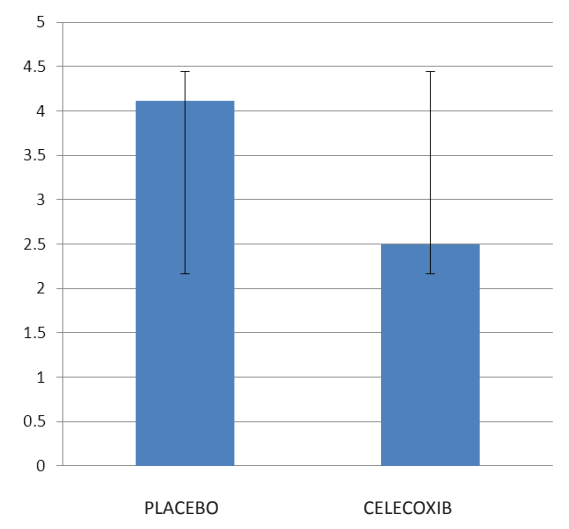

Figure1: The mean pain score for the entire day time
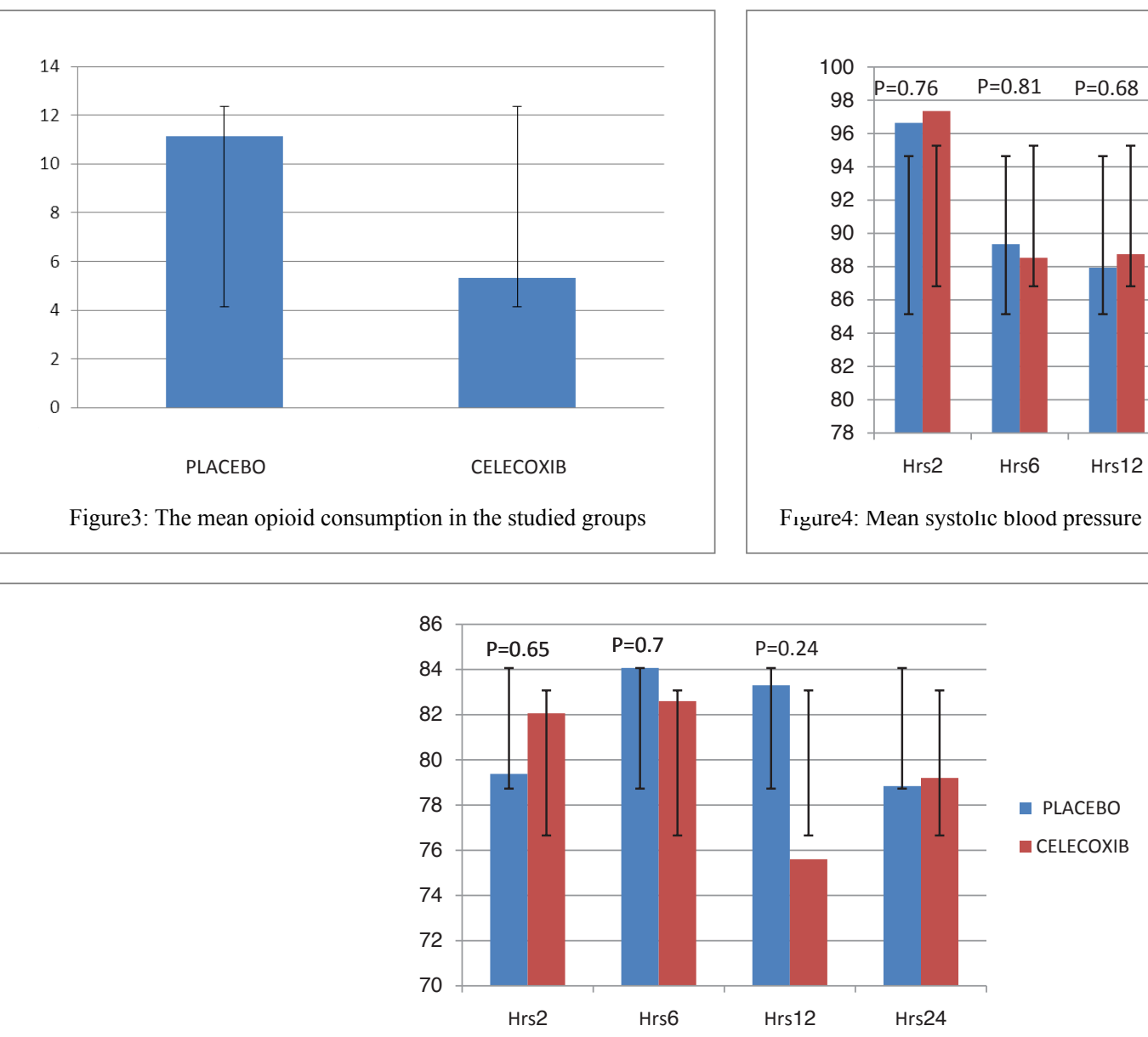

Figure 5: Heart Rate in different times after surgery

\section{Discussion}

The present study showed the superiority of celecoxib in pain control at least for two hours in addition to the total painless time period after surgery. In addition, celecoxib could perfectly decrease opioid requirement to control postoperative pain with no adverse effects.

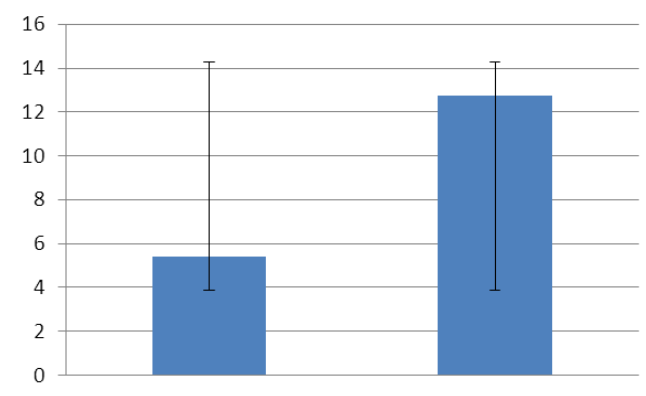

PLACEBO

CELECOXIB

Figure2: Time-based comparison of painless periods between the groups

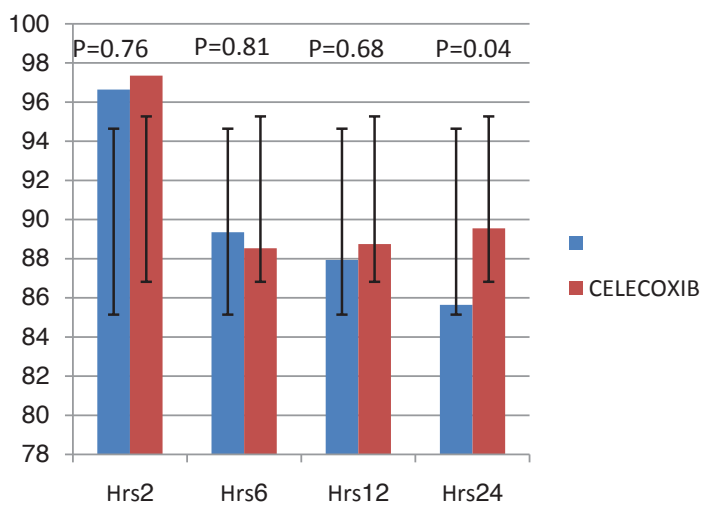

Fıgure4: Mean systolic blood pressure in ditferent times after surgery 
Al-Sukhun and colleagues in 2012 publish a report of their trial which compares low dose of celecoxib and NSAIDs in pre-emptive analgesia through minor oral surgery to find out the absolute superiority of celecoxib [8]. On the line with ours, Kashefi's trial in 2012 shows an early superiority of celecoxib against acetaminophen and placebo fading before 12 hours during pre-emptive analgesia for orthopedic surgery [9]. This is while, unlikely, a study in 2010 realized that celecoxib had no superiority comparing placebo but etoricoxib left both of them behind in terms of analgesic efficacy through pre-emptive analgesia for arthroscopy [10]. This trial reports no different adverse effects in the three groups of study which was similar to what we found.

It seems that pre-emptive analgesia is a popular way to increase patient's satisfaction after surgery and some have focused on it to prove its advantages like a retrospective work by Trabulsi in 2010 which shows the superiority of PA compared with standard postoperative analgesic regimen, especially in the reduction of opioid use like what the present study demonstrates [11]. A similar study compares celecoxib with itself as perioperative or postoperative analgesia [12]. This study concludes that the named medication is much more effective when used as perioperative medication, not only in pain control, but also in recovery acceleration as well as patient's satisfaction. Sinatra, in a review article, raised also the plasma half-life of COX-2 inhibitors, especially in "coxibs" as a helpful factor to provide certain clinical advantages in postoperative pain management [1].

To sum up, the rather vast number of adverse effects of NSAIDs and opioids has provided a setting through recent decades to grow the global demand for COX-2 inhibitors, especially in pain management in surgery considering their superiority in direct analgesic efficacy and perfect safety and plasma half-life as well as better tolerance by patients.

\section{References}

1. Sinatra R (2002) Role of COX-2 inhibitors in the evolution of acute pain management. J Pain Symptom Manage 24: S18-27.

2. Miller RD, Fleisher LA, Johns RA (2005) Miller's Anesthesia, sixth Edition 2005, Churchill living stone. Volume II, chapter 72: 2729-2762.

3. Gheshlaghi-Azar N, Kheradmand R (2006) Comparative evaluation of Celecoxib (a Cox-2 inhibitor) versus Ibuprofen in control of pain due to Acute Apical Periodontitis. J Dent Sch GYEAR 24: 363-368.

4. Reuben SS, Buvenandran A, Katz B, Kroin JS (2008) A prospective randomized trial on the role of perioperative celecoxib administration for total knee arthroplasty: improving clinical outcomes. Anesth Analg 106: $1258-1264$
5. Ekman EF, Wahba M, Ancona F (2006) Analgesic efficacy of perioperative celecoxib in ambulatory arthroscopic knee surgery: A double-Blind,Placebo-controlled study. Arthroscopy 22: 635-642.

6. Huang YM, Wang CM, Wang CT, Lin WP, Horng LC, et al. (2008) Perioperative celecoxib administration for pain management after knee arthroplasty: a randomized controlled study. BMC Musculoskeletal Disord 9: 77.

7. Lim SS, Tan PC, Sockalingam JK, Omar SZ (2008) Oral celecoxib versus oral diclofenac for post-perineal repair analgesia after spontaneous vaginal birth: A randomized trial. Aust N Z J Obstet Gynaecol 48: 71-77.

8. Al-Sukhun J, Al-Sukhun S, Penttilä H, Ashammakhi N, Al-Sukhun R (2012) Preemptive analgesic effect of low doses of celecoxibis superior to low doses of traditional nonsteroidal anti-inflammatory drugs. J Craniofac Surg 23: 526-529.

9. Kashefi P, Honarmand A, Safavi M (2012) Effects of preemptive analgesia with celecoxib or acetaminophen on postoperative pain relief following lower extremity orthopedic surgery. Adv Biomed Res 1: 66.

10. Boonriong T, Tangtrakulwanich B, Glabglay P, Nimmaanrat S (2010) Comparing etoricoxib and celecoxib for preemptiveanalgesia for acute postoperative pain in patients undergoing arthroscopic anterior cruciate ligament reconstruction: a randomized controlled trial. BMC Musculoskelet Disord 11: 246.

11. Trabulsi EJ, Patel J, Viscusi ER, Gomella LG, Lallas CD (2010) Preemptive multimodal pain regimen reduces opioidanalgesia for patients undergoing robotic-assisted laparoscopic radical prostatectomy. Urology 76: 1122-1124.

12. Shen B, Tang X, Yang J, Li Y, Zhou ZK, et al. (2009) Effects of perioperative administration of celecoxibon pain management and recovery of function after total knee replacement. Zhonghua Wai Ke Za Zhi 47: 116-119.

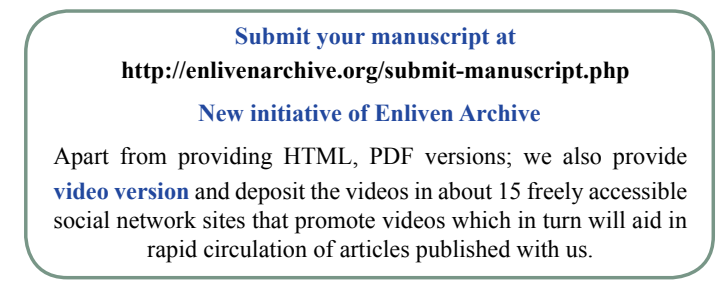

